\title{
Impacts of a changing climate and low land use on a Tropical Montane Cloud Forest
}

\author{
I. Torres ${ }^{1}$, J. E. González ${ }^{2}$ \& D. E. Comarazamy ${ }^{2}$ \\ ${ }^{1}$ Department of Mechanical Engineering, \\ University of Puerto Rico-Mayagüez, Puerto Rico \\ ${ }^{2}$ Department of Mechanical Engineering, Santa Clara University, USA
}

\begin{abstract}
Tropical Montane Cloud Forests (TMCF) are a primary source of fresh water in tropical locations and are highly sensitive to changes in vegetation, sea surface temperatures, and global climate, such is the case in the El Yunque Rain Forest, in Northeastern Puerto Rico. Climatological analyses of this TMCF reveal changes in the region's climate reflected in increasing moisture content and surface air temperature. Historical changes in the low lands due to agriculture and urban sprawl are suspected to be a source of the climate variation. The focus of this paper is to quantify the climate impacts of changes in land use close to coastal TMCFs, using El Yunque during the dry season as the test case. To achieve this goal, the research makes use of high-resolution remote sensing information and surface weather stations, combined with the Regional Atmospheric Modeling System (RAMS). The coupled and individual effects of land use and global climate change are investigated in detail by performing an ensemble of numerical simulations that represent past and present land use conditions, and past and present climate. Results indicate significant impacts in increasing air temperatures, reduction in cloud base heights, and increases in precipitation in the highlands and are attributed to increases of sea surface temperatures. Historical forestation tends to mitigate these global warming effects in the low land areas, while urbanization tends to augment them.
\end{abstract}

Keywords: dry season, land use, Puerto Rico, RAMS, Tropical Montane Cloud Forest. 


\section{Introduction}

The island of Puerto Rico is located in the northeast corner of the Caribbean Basin where the Atlantic Ocean and the Caribbean Sea converge, approximately between $18^{\circ}-18.5^{\circ} \mathrm{N}$ and $65.30^{\circ}-67.25^{\circ} \mathrm{W}$. The island has large areas covered by mountains, which have an influential role on its climate. Part of this system of mountainous terrain is the El Yunque Rain Forest, a Tropical Montane Cloud Forest (TMCF) also known as the Luquillo Experimental Forest (LEF), located in Northeastern Puerto Rico, around $40 \mathrm{Km}$ southeast of the capital city of San Juan (see Figure 1). A TMCF is defined as an area where the mountains are frequently enveloped by tradewind-derived orographic clouds and mist in combination with convective rainfall [1]. El Yunque is also a protected natural area with elevations from about $100 \mathrm{~m}$ to $1075 \mathrm{~m}$ above mean sea level. The climatology of the island presents a bimodal pattern of the monthly-accumulated precipitation, where the two modes are called the Early and Late Rainfall seasons, respectively. The eastern part of Puerto Rico shows a similar climatological pattern as the rest of the island in terms of precipitation and average temperature (Figure 2) [2-5]. The Early Rainfall Season, also referred to as the Dry Season, spans from late December to March when both precipitation and near surface air temperature are at a minimum.

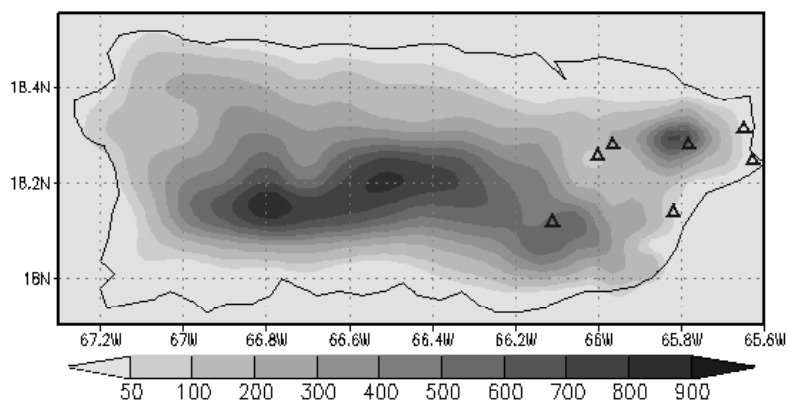

Figure 1: Puerto Rico elevation map (meters). Marks represent locations of the stations depicted in Figure 2.
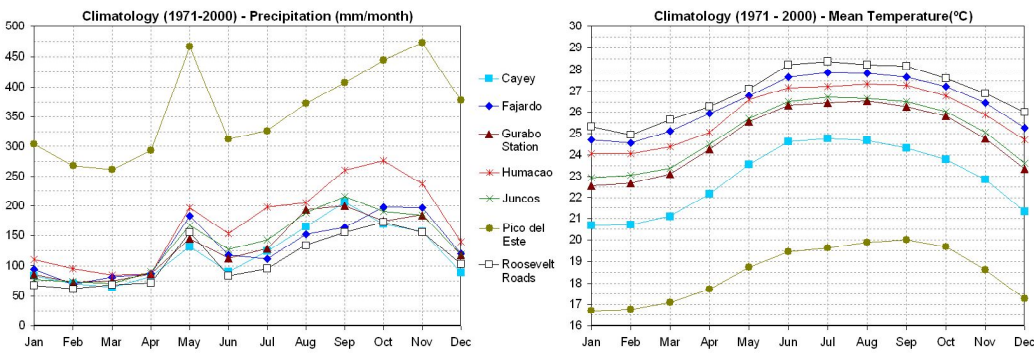

Figure 2: Climatology of monthly-accumulated precipitation in $\mathrm{mm} / \mathrm{month}$ (left) and surface temperature (right) in El Yunque. The locations of the stations are shown in Figure 1. 
Given the proximity of El Yunque to the coast, its climate is greatly influenced by the surrounding sea surface temperatures (SSTs) [6]. In conditions of global warming, assumed to be mainly a consequence of an increase in global concentrations of green house gases [7], SSTs have been observed to increase impacting regions with maritime climates. Land cover and land use (LCLU) changes, mainly due to deforestation and development, also tend to have a climatic impact in sensitive regions such as TMCF [8-10]. Where the scale of influence of land-use is very small compared to global warming, it has an important effect and consequences in local areas. Quantifying the impact of both land use change and climate change, and their combined effect with a combination of data analysis and numerical simulations, is the main focus of the research presented in this paper.

\section{Data analysis}

\subsection{Sea surface temperature around Puerto Rico}

To characterize the SSTs around Puerto Rico, the Smith and Reynolds Extended Reconstructed SST v.2 at $2^{\circ}$ grid resolution was used [11]. Figure 3 shows monthly SST anomalies spatially averaged between $76^{\circ}-56^{\circ} \mathrm{W}$ and $10^{\circ}-26^{\circ} \mathrm{N}$ during the Dry Season since 1950. The El Niño Southern Oscillation (ENSO) is a factor that affects the Atlantic and Caribbean SSTs; with one to two months lag during warm and cold events, respectively, based on the ENSO3 index [12, 13]. Figure 4 shows the monthly ENSO3 and ENSO1+2 (1-2 months lag) anomalies during the Dry Season. There appears to be a clear correspondence between ENSO and SSTs during the Dry Season in the Caribbean.

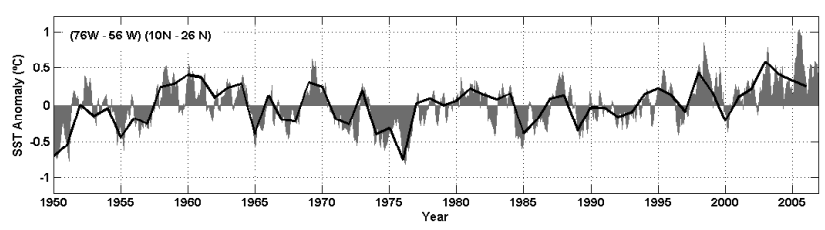

Figure 3: Monthly SST anomaly around Puerto Rico $\left[76^{\circ} \mathrm{W}-56^{\circ} \mathrm{W}\right.$ and $10^{\circ} \mathrm{N}$ $-26^{\circ} \mathrm{N}$ ], black line represents the mean value for the dry season.

\subsection{High resolution land use classification}

The ATLAS Mission was conducted in February of 2004 and consisted of a 14channel remote sensor mounted on a Lear jet [14]. During the mission the sensor was flown over El Yunque and the San Juan Metropolitan Area (SJMA), producing a $10 \mathrm{~m}$ horizontal resolution dataset (www.cmg.uprm.edu/atlas). The airborne campaign was complemented with a large number of sensors deployed around El Yunque to measure air and dew temperatures, relative and absolute humidity in the direction of the easterly trade winds (Figure 5). A spatial interpolation of the ground sensors (mostly $\mathrm{HOBO}^{\mathrm{TM}}$ 's sensors) data was 
performed in a grid that covered the El Yunque region (Figure 6). It was noticed that the absolute humidity and the minimum dew temperatures do not occur at the topographic peaks. Additionally, the data showed that the mean temperature on the area does not have a linear profile as reported in other studies [5], with areas showing mean minimum temperatures off peak of the mountain. Consequently the maximum values of relative humidity do occur at the maximum altitudes.

\subsection{Urban development - land use 2004}

The urban concrete density per $\mathrm{km}^{2}$ in the eastern region of Puerto Rico was obtained from the 10m ATLAS data as shown in Figure 7, presenting a similar visual pattern as other research projects [15]. Important to point out, and essential for the objectives of this research, are the developing urban areas around El Yunque, the close proximity of the SJMA and Caguas, northwest and southwest of El Yunque, respectively.
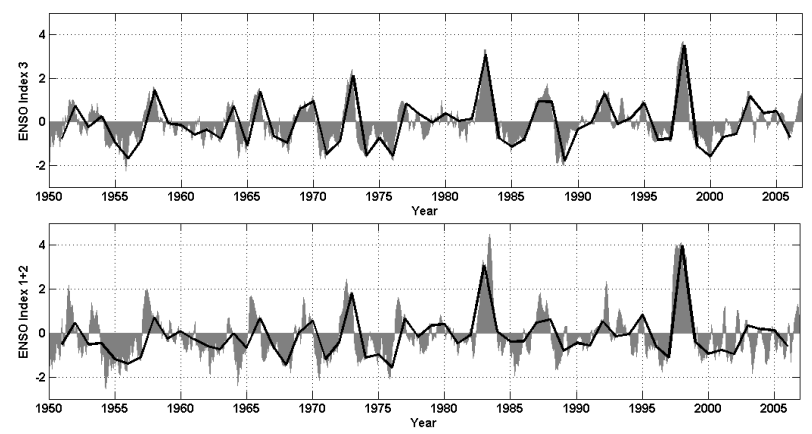

Figure 4: $\quad$ Monthly ENSO anomaly for ENSO3 (top) and ENSO1+2 (bottom), black line represents the mean value between November and January months.

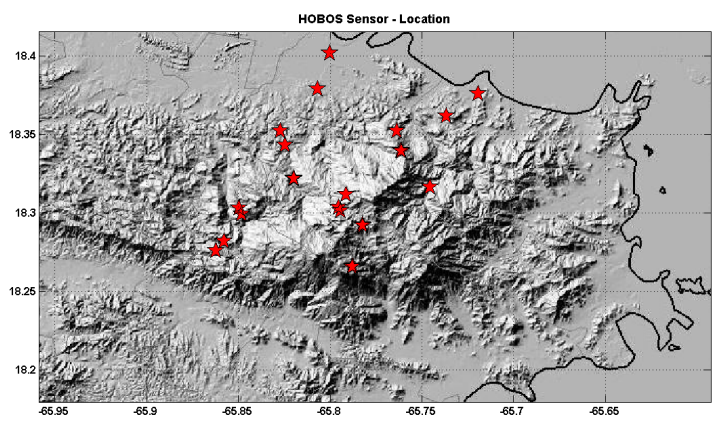

Figure 5: Location of the HOBOS sensors during the ATLAS mission campaign. 

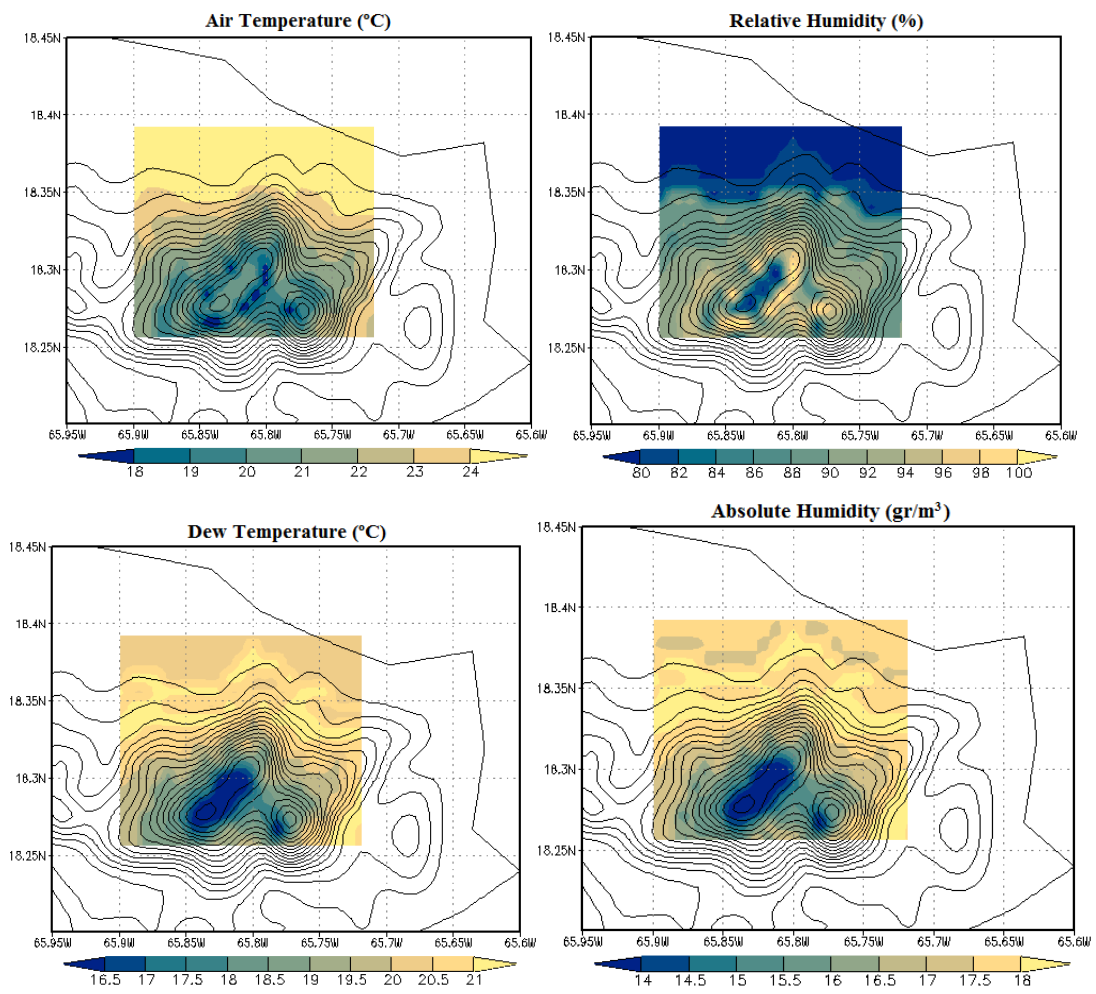

Figure 6: Mean February 2004 HOBOS sensors data field interpolation around El Yunque for: (a) temperature $\left({ }^{\circ} \mathrm{C}\right)$; (b) relative humidity (\%); (c) dew temperature $\left({ }^{\circ} \mathrm{C}\right)$; (d) absolute humidity $\left(\mathrm{g} / \mathrm{m}^{3}\right)$.

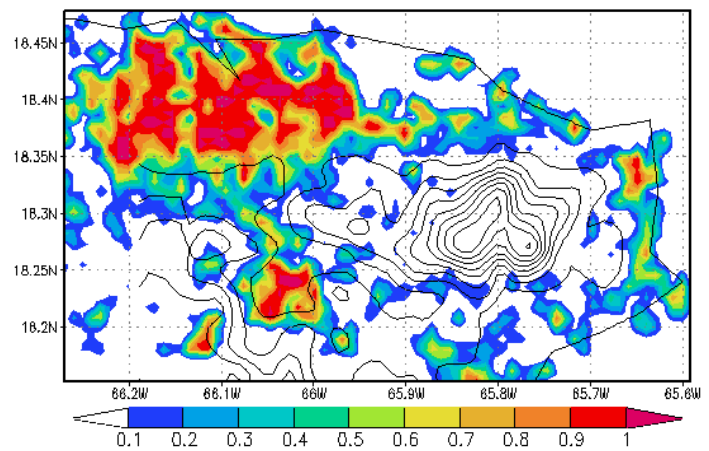

Figure 7: $\quad$ ATLAS derived urban concrete density, $\mathrm{km}^{-2}$ (February 2004). 


\section{Numerical experiments}

\subsection{Model configuration and methodology}

The Regional Atmospheric Modeling System (RAMS) was selected as the main research tool for the study presented here. RAMS is a highly versatile numerical code developed at Colorado State University for simulating a wide variety of phenomena at different time and spatial scales [16, 17]. A three-grid configuration was used where each grid covered the Caribbean Basin, the island of Puerto Rico, and the El Yunque and surrounding areas at 100, 5, and $1 \mathrm{~km}$ horizontal resolution respectively (Figure 8). The terrain following vertical coordinate was specified with a constant stretching ratio of 1.1 until a grid spacing of $1 \mathrm{~km}$ was reached. The modelling system was initialized with the $2.5^{\circ}$ resolution NCEP Reanalysis data and the Reynolds-Smith SST data. All simulations ran for one month, namely February 2004. In order to quantify the individual and combined impact of LCLU changes and different concentration a warming global climate (GHG), an ensemble of model simulations was proposed and it is presented in Table 1. The following operations applied to different atmospheric variables: $\mathrm{C} 1-\mathrm{C} 2$ represents the individual influence of GHG; $\mathrm{C} 1-$ C3 shows the local LCLU influence; and C1-C4 presents the combined effect produced in the area. To reduce the ENSO effect on the Caribbean and therefore its influence on the simulations, the average ENSO3 index from November to January during 8 years was taken as a reference and compared to the ENSO3 index during the 2004 Dry Season, both diverging by only 0.05 . Then a February in the past was selected with a similar ENSO3 index and taken as the average past conditions. This average February is then paired with a 1977-78 LCLU classification of Puerto Rico $[18,19]$ representing deforested and agriculture areas with less urban development than at present to complete both scenarios (Figure 9).

\subsection{Model validation}

To calibrate the model results, air temperature measurements taken during the ATLAS mission (see Figures 5-6) were compared with simulated 2-m AGL air
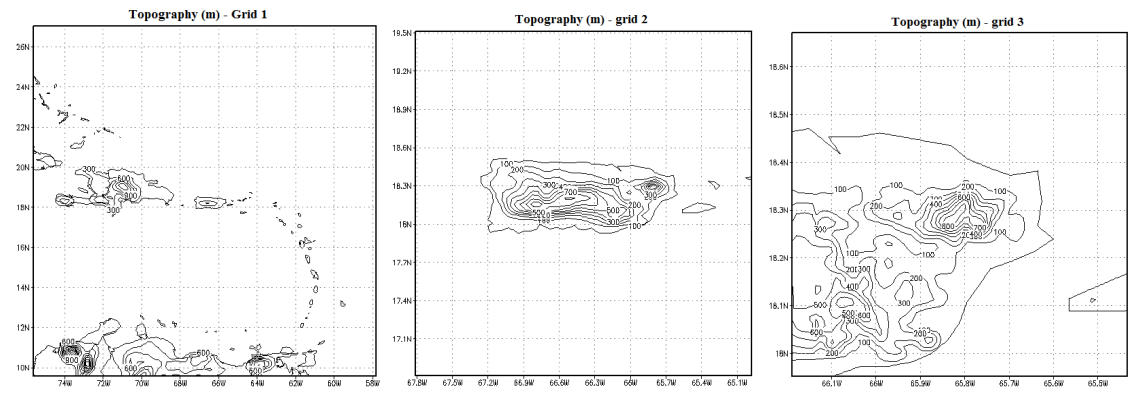

Figure 8: Topography $(\mathrm{m})$ of three grids configured in RAMS. 


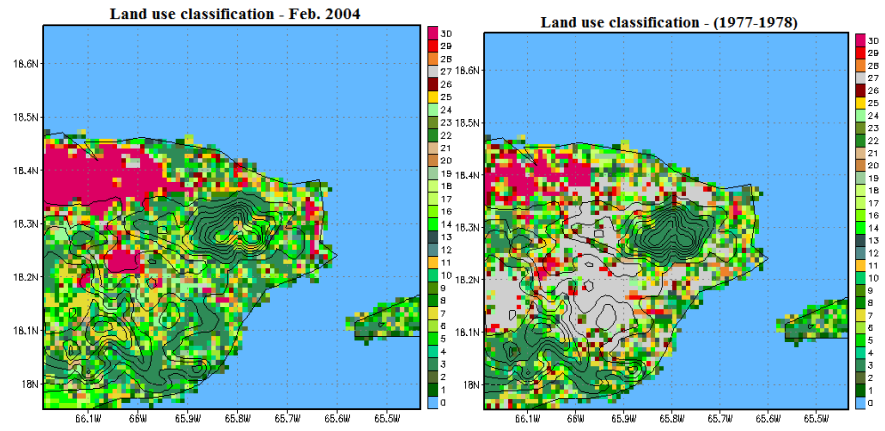

Figure 9: Predominant land use classification in RAMS for the present (2004) and average past conditions (1977-1978).

Table 1: $\quad$ RAMS configurations used to analyze LCLU and GHG effects.

\begin{tabular}{|l|l|l|}
\hline Index & LCLU & GHG \\
\hline C1 & Present & Present \\
\hline C2 & Present & Past \\
\hline C3 & Past & Present \\
\hline C4 & Past & Past \\
\hline
\end{tabular}

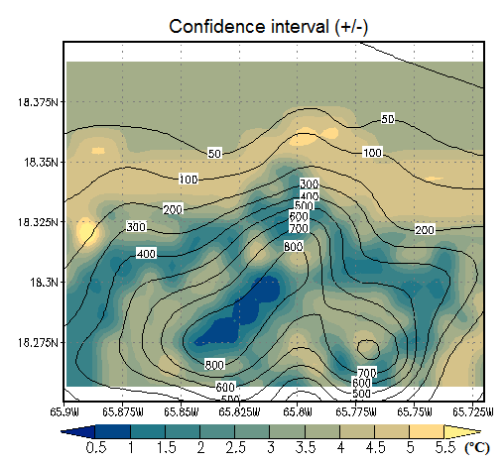

(a)

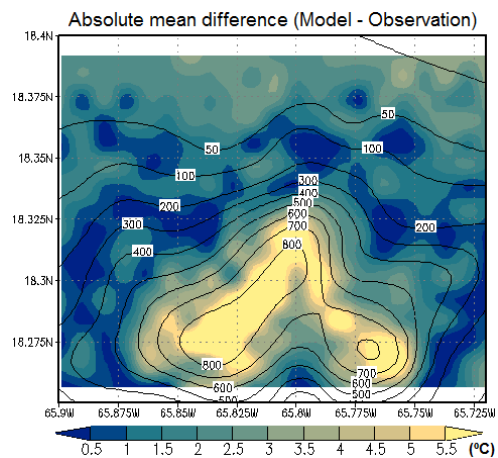

(b)

Figure 10: (a) Confidence interval (+/-) of measured monthly mean air temperatures. (b) Absolute difference between monthly average 2m AGL air temperatures simulated by RAMS and air temperatures measured by HOBO stations. Both panels are for February 2004.

temperatures. Figure 10a depicts the confidence interval of measured temperatures in El Yunque, where the data was interpolated to a regular grid with the same specifications as RAMS grid 3; this plot shows less variability of the measured data above $800 \mathrm{~m}$. The maximum variability is found in lowland areas between sea level and 200m above sea level (ASL), between 500 and 700m ASL data variability increases surrounded by lower values. The maximum values are 
shown near the coast and minimum values at the peaks, but the variability lapse rate is not linear. Figure 10b shows the difference between the monthly averaged 2-m above ground level (AGL) simulated air temperatures and the measured temperatures for February 2004. There is good accuracy for most of the grid. However, above $700 \mathrm{~m}$ there is a rapid increase in this difference, reaching a maximum of $6^{\circ} \mathrm{C}$ in the peak of el Yunque, above the 800 meters. The simulation shows lower values than reported by the measured data with greater values and less variability in this area.

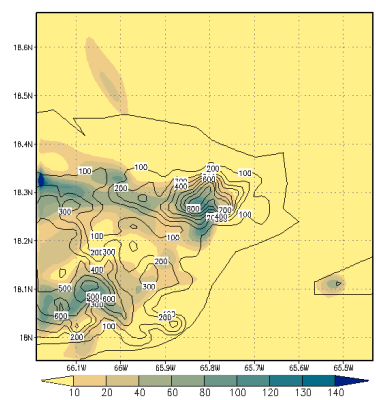

(a)

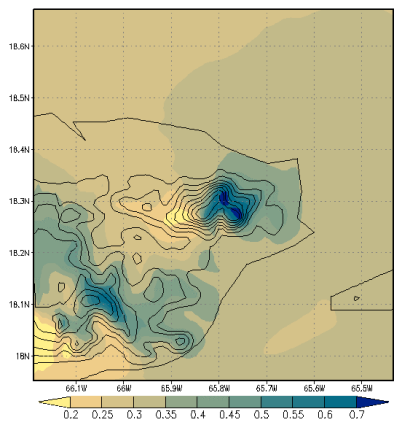

(c)

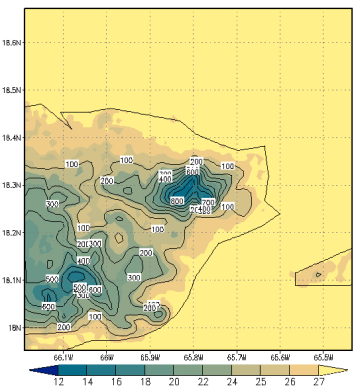

(b)

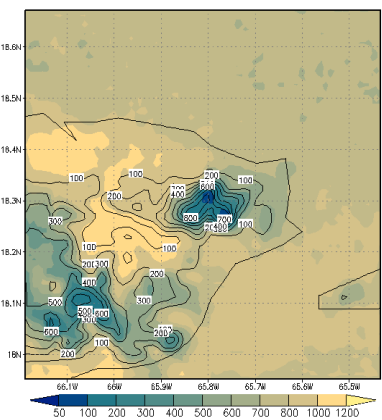

(d)

Figure 11: Simulated (a) accumulated precipitation, mm; (b) monthlyaveraged temperature $2-\mathrm{m} \mathrm{AGL},{ }^{\circ} \mathrm{C}$; (c) cloud cover, \%; and (d) cloud base (m AGL) for February 2004.

\subsection{Simulation results for February 2004}

The February 2004 results from the C1 simulation (Table 1) for monthlyaccumulated precipitation, and monthly averaged 2-m AGL air temperature, cloud cover, and cloud base heights are shown in Figure 11. The accumulated precipitation panel clearly shows the orographic influence on rainfall in El Yunque and surrounding areas, as does the simulated air temperatures 2-m AGL. The monthly averaged simulated cloud base height shows a mean cloud base between 800-1000m AGL, reaching a minimum near the mountain peaks. Because of the orographic effect on precipitation and cloud cover, the maximum 
values are found windward of El Yunque, which are accompanied by a low cloud base. On the leeward areas of El Yunque there are low cloud cover values with an increase of cloud base heights influenced by wind convergence and vertical motions. Over the SJMA high average cloud base heights are found, possibly as a consequence of the convective nature of the urban heat island effect [20].

\subsection{The LCU and GHG effects on temperature and precipitation}

The global warming effects (C1-C2) in the air temperature 2 meters AGL are depicted in Figure 12(a), where the actual increase in air temperature is approximately $1.5^{\circ} \mathrm{C}$ warmer than similar average past conditions. SJMA clearly presents an increasing in local average temperatures, reaching maximum increases in the southwestern areas as a consequence of the heat transported from the high density urban areas along the north easterly trade winds. The land use change (C1-C3) also has an impact in air temperatures near the surface (Figure 12b). The land use change reduces the air temperature from the past agricultural and grass-land areas for about the same magnitude as the increase in temperature caused by GW effects. The coupled effect of GW and Land use change (C1-C4) is shown in Figure 12c presenting the total increased air temperature near the surface as a result of GW and high density urban areas. The cooler areas are produced by the land use change, which generates decreasing temperatures overriding the increasing effect by GW. Decreasing air temperatures in eastern Puerto Rico, around and inside El Yunque, mean that land use change is reducing the GW effect in this area since 1977-1978, which is the reference time for the past land use. This shows that emerging and recovery forests [21] and reduction in the agricultural zones [22], in the lowland areas are mitigating the warming trends in the zone.

Accumulated precipitation presents the spatial variability as shown in Figure 13. There is an increasing tendency in highland areas and decreasing tendencies in lowland areas. In lowland areas $(<300 \mathrm{ASL})$ there is a reduction in the average accumulated precipitation of similar magnitude; i.e. LULC and GHG have similar effects in the lowland areas during the dry season. In highland areas ( $>300$ ASL) there is a larger influence of GW in this region providing $97 \%$ of the total effect in the mountain regions; which means that LULC changes in the upwind lowland areas do not have significant effects in the precipitation in a TMCF.

\section{Conclusions}

The increasing SSTs are causing increasing air temperatures in tropical coastal areas and higher humidity content at high atmospheric altitudes. This may be aggravated by rapid changes in land uses including urbanization. The case of northeastern Puerto Rico was investigated and it was found that the warmer and more humid air is transported along the trade winds, generating low formation of orographic clouds (reduced cloud base) in the windward areas of the tropical rain 
forest areas. For the case of El Yunque in Puerto Rico, the climate was found to be more sensitive to changes in the SST than to the ongoing development urban areas. This may be true for other tropical coastal locations.

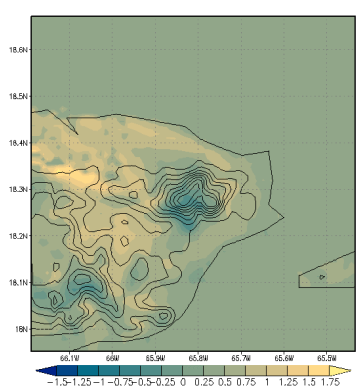

(a)GHGs effects

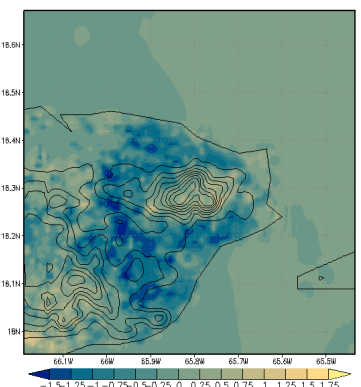

(b) LULC effects

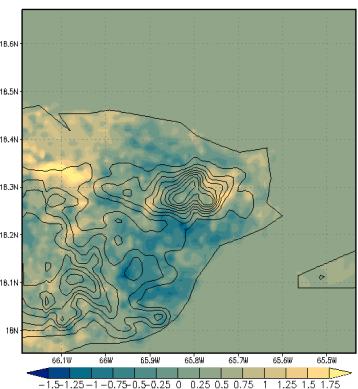

(c) Coupled effects

Figure 12: Average simulation air temperature difference at 2 meters AGL.

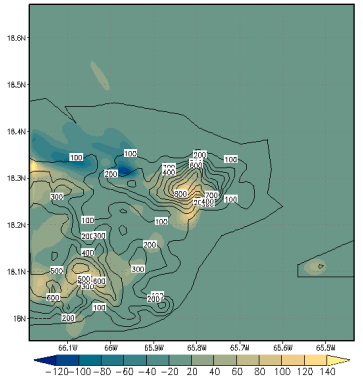

(a) GW effects -

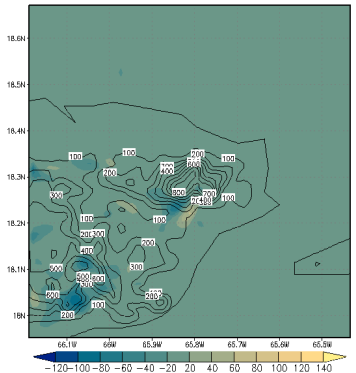

(b) LULC effects

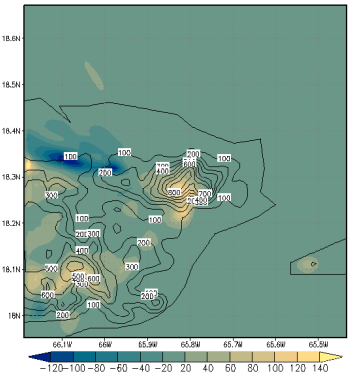

(c) Coupled effects

Figure 13: $\quad$ Simulated accumulated monthly precipitation difference $(\mathrm{mm})$.

\section{Acknowledgements}

This Research is supported by NASA - EPScOR Program, University of Puerto Rico. Mayagüez Campus. The simulations were made possible by grant number P20 RR-016470 from the National Center for Research Resources (NCRR), a component of the National Institutes of Health (NIH).

\section{References}

[1] Still, C., P. Foster, and S. Schneider, 1999: Simulating the effects of climate change on tropical montane cloud forest. Nature, 398, 608-610.

[2] Kottek, M., J. Grieser, C. Beck, B. Rudolf, and F. Rubel, 2006: World map of the kvppengeiger climate classification updated. Meteorol. Z., 15, 259-263. 
[3] Peel, M., B. Finlayson, and T. McMahon, 2007: Updated world map of the koppen-geiger climate classification. Hydrol. Earth Syst. Sci. Discuss., 4, 439-473.

[4] Scatena, F., 2006: Climate and hydrology. Document available at: http://luq.lternet.edu/research/projects/climate_hydrology_description.html.

[5] Melendez-Colom, E., 2004: Regression relationships of air temperature and elevation along an elevation gradient in the luquillo experimental forest (lef), Puerto Rico. Online. http://luq.lternet.edu/data/temp/ bistempdata/Bis-temp.htm.

[6] Waide, R. C., M. Angeles, J. E. Gonzalez, C. a. Hall, A. Lugo, D. J. Murphy, J. R. Ortiz-Zayas, and N. D. Ramirez, 2006: Factors influencing the changing climate of the Luquillo mountains, Puerto Rico. Presented at: Caribbean Climate Symposium - University of Puerto Rico at Mayagüez.

[7] IPCC, 2007: Climate Change - Fourth Assessment. Intergovernmental Panel of Climate Change.

[8] Lawton R. O., Nair, U. S., Pielke Sr., R. A., and Welch, R. M., 2001. Climatic Impact of tropical lowland deforestation on nearby montane cloud forests. Science 294, 584-587.

[9] Ray, D. K., Nair, U. S., Lawton, R. O., Welch, R. M., and Pielke Sr., R. A. 2006. Impact of land use on Costa Rican tropical montane cloud forests: Sensitivity of orographic cloud formation to deforestation in the plains. Journal of Geophysical Research 111, D02108, doi:10.1029/2005JD006096.

[10] Van der Molen, M., A. Dolman, M. Waterloo, and L. Bruijinzeel, 2006: Climate is affected more by maritime than by continental land use change: A multiple scale analysis. Elsevier - Global and Planetary Change, 54, 128-149.

[11] Smith, T. and R. Reynolds, 2004: Improved extended reconstruction of SST (1854 - 1997). Journal of Climate, 17, 2466-2477.

[12] Giannini, A., J. C. Chang, M. A. Cane, Y. Kushnir, and R. Seager, 2001: The enso teleconection to the tropical ocean: Contributions the remote and local ssts to rainfall variability in the tropical americas. Journal of Climate, 14, 4530-4544.

[13] Chikamoto, Y. and Y. Tanimoto, 2005: Role of specific humidity anomalies in the Caribbean sst response to enso. Journal of the Meteorological Society of Japan, 83(6), 959-975.

[14] González, J., J. Luvall, D. Rickman, D. Comarazamy, A. Picón, E. Harmsen, H. Parsiani, N. Ramírez, R. Vásquez, R. Williams, R. Waide, and C. Tepley, 2005: Urban heat island developing in coastal tropical cities. EOS Transactions, 86(42), 397-412.

[15] Martinuzzi, S., W. Gould, and O. R. Gonález, 2007: Land development, land use, and urban sprawl in Puerto Rico integrating remote sensing and population census data. Landscape and urban planning, 79, 288-297.

[16] Pielke, R., W. Cotton, R. Walko, C. Tremback, W. Lyons, L.D. Grasso, M. Nicholls, M. Moran, D. Wesley, T. Lee, and J. Copeland, 1992: A 
comprehensive meteorological modeling system - rams. Meteorology and Atmospheric Physics, 49, 69-91.

[17] Cotton, W. R., Pielke Sr., R. A., Walko, R. L., Liston, G. E., Tremback, C. J., Jiang, H., McAnelly, R. L., Harrington, J. Y., Nicholls, M. E., Carrio, G. G., and McFadden, J. P., 2003. RAMS 2001: Current status and future directions. Meteorology and Atmospheric Physics 82, 5-29.

[18] Helmer, E., 2004: Forest conservation and land development in Puerto Rico. Landscape Ecology, 19, 29-40.

[19] Kennaway, T. and E. Helmer, 2007: The forest types and ages cleared for land development in Puerto Rico. GIScience \& Remote Sensing, 44(4). In Press.

[20] Velazquez-Lozada, A., Gonzalez, J. E., and Winter, A., 2006. Urban heat island effect analysis in San Juan, Puerto Rico. Atmospheric Environment 40, 1731-1741.

[21] Lugo Ariel E. and Helmer Eileen. "Emerging Forest on Abandoned Land: Puerto Rico's New Forests." Forest Ecology and Management. 190 (2004): 145-161.

[22] FAO. Global Forest Resources Assessment 2005. Forestry Paper 147., Rome: Food and Agricultural Organization of the United Nations., 2005. 